\title{
O PERCURSO NARRATIVO DOS ROMANCES POLICIAIS MAIS VENDIDOS NO BRASIL NA DÉCADA DE 1970:
}

Sanção cognitiva ou sanção pragmática?

THE ROUTE NARRATIVE OF NOVEL POLICE IN THE 70'S:

Sanction cognitive or sanction pragmatic?

Fernanda Massi e Arnaldo Cortina UNESP - Universidade Estadual Paulista

\begin{abstract}
Resumo: Este trabalho foi elaborado a partir de um levantamento dos romances policiais mais vendidos no Brasil durante a década de 1970. O corpus da pesquisa contém vinte e seis obras que foram analisadas e comparadas sob uma perspectiva semiótica. Partindo da leitura desse corpus, fizemos uma análise comparativa das obras e as dividimos em dois tipos de romances policiais: os que apresentaram em sua constituição narrativa uma sanção cognitiva e os que apresentaram uma sanção pragmática. Em nossa análise, verificamos o percurso de cada um dos enredos dos romances do corpus, buscando compreender as justificativas da escolha que cada um dos sujeitos enunciadores fez para organizar sua narrativa e as implicações que essas escolhas tiveram para o desenlace da narrativa. Ainda em relação a esse percurso narrativo, procuramos verificar também quais foram os elementos responsáveis pelo interesse do leitor por determinadas obras, o que significou estarem entre os best-sellers da época. Por fim, realizamos uma análise comparativa entre os dois tipos de sanção para verificar qual deles aparecia com mais frequiência e que diferenças fundamentais cada uma dessas sanções provoca no desenlace dos romances.
\end{abstract}

Palavras-chave: romance; policial; sanção; cognitiva; pragmática.

Abstract: This work is a result of a research of police novels sold in Brazil during the 70's. The research corpus was constituted of twenty six books that were analyzed and compared trough a semiotic's perspective. From the reading of these novels we've done a comparative analysis of the books and classified them in two types of police novel: those who presented in their narrative constitution a cognitive sanction and those who show a pragmatic sanction. In our analysis, we verified the route of each plot from the selected police novels, aiming to understand the reasons that lead to the choice on each one of the enunciators did to organize their narrative. We also tried to understand the implications that these choices brought to the outcome of it. Considering the same narrative route, we also intended to verify the elements that were responsible for the interest of the reader to a certain kind of text, the reason which leads them to be the best-sellers of the period. Finally, we made a comparative analysis between the two types of sanctions verifying which of them appeared more frequently and which fundamental differences they provoke to the final outcome of the novels.

Keywords: novel; police; sanction; cognitive; pragmatic. 
O romance policial tem suas normas; fazer "melhor" do que elas pedem é ao mesmo tempo fazer "pior"; quem quer "embelezar" o romance policial faz "literatura", não romance policial. (TODOROV, 1970, p. 95).

No final do século XIX, Edgar Allan Poe (1809-1849) criou a figura do detetive Dupin, que estreou nas narrativas "Os crimes da Rua Morgue" (1841), "O mistério de Marie Roget" (1842) e "A carta roubada" (1845). Essas narrativas ficcionais tinham o mistério como principal característica e, para justificar a presença do detetive, incorporaram a investigação policial. Assim, surgiram mais duas personagens indispensáveis a qualquer tipo de investigação, um criminoso e uma vítima; juntos, esses três sujeitos compunham o sustentáculo do chamado romance policial.

Em geral, os crimes cometidos nesses romances são os assassinatos, por ser esse o extremo da violência de um ser humano sobre outro, já que cessa a vida de um modo brusco. $\mathrm{O}$ assassinato é um crime romanticamente superior, carregado de diversas paixões entre os envolvidos, seja a vítima, que teme a morte, o criminoso, que tem motivos para realizar o assassinato, e as pessoas envolvidas com a vítima, que sofrem com sua ausência e que, em geral, acionam o fazer do detetive. Nas narrativas policiais, geralmente, não há muitas personagens envolvidas no crime, pois o criminoso guarda o segredo sobre sua identidade durante toda a narrativa, que só é descoberta, ao final, pelo detetive. Pode ocorrer também de o crime ser cometido por mais de um sujeito e, nesse caso, não temos um saber, mas sim um fazer compartilhado.

Embora os romances apresentem diferenças no que se refere às motivações para o crime, ao perfil das vítimas, aos instrumentos utilizados durante o assassinato, entre outras, há uma estrutura fixa que a semiótica, tal como proposta inicialmente por Algirdas Julien Greimas (1975), denomina esquema narrativo canônico, presente em todo e qualquer texto. No caso dos romances policiais, há um destaque maior, nesse esquema, para o percurso narrativo de dois sujeitos do fazer, indispensáveis à trama: o sujeito-criminoso e o sujeitodetetive. Segundo a semiótica discursiva, o esquema narrativo contém quatro programas narrativos: a manipulação, a competência, a perfórmance e a sanção. Na narrativa policial, a perfórmance do detetive corresponde, no percurso do criminoso, a uma sanção, ou seja, é nesse último programa narrativo que os dois percursos se encontram.

No programa da manipulação, o destinador-manipulador atribui ao destinatário-sujeito a competência modal necessária à ação, ou seja, o criminoso é manipulado a cometer o crime e o detetive a fazer a investigação. Nos romances policiais estudados pudemos observar as quatro formas previstas pela semiótica para o percurso da manipulação, quais sejam, a tentação, a intimidação, a provocação e a sedução. Em geral, nos romances policiais em que o sujeito criminoso foi manipulado pela paixão da vingança, outro crime anterior à narrativa principal - foi o causador da manipulação. Barros (2005, p.33) organiza os tipos de manipulação, segundo o critério "da competência do manipulador, ora sujeito do saber, ora sujeito do poder, e o da alteração modal, operada na competência do sujeito manipulado", conforme a tabela a seguir:

\begin{tabular}{|c|c|c|}
\hline $\begin{array}{c}\text { Tipo de } \\
\text { manipulação }\end{array}$ & $\begin{array}{c}\text { Competência do destinador- } \\
\text { manipulador }\end{array}$ & $\begin{array}{c}\text { Alteração na } \\
\text { competência do }\end{array}$ \\
\hline
\end{tabular}




\begin{tabular}{|c|c|c|}
\hline & & destinatário \\
\hline PROVOCAÇÃO & $\begin{array}{c}\text { SABER (imagem negativa do } \\
\text { destinatário) }\end{array}$ & DEVER-FAZER \\
\hline SEDUÇÃO & $\begin{array}{c}\text { SABER (imagem positiva do } \\
\text { destinatário) }\end{array}$ & QUERER-FAZER \\
\hline INTIMIDAÇ̃̃̃O & PODER (valores negativos) & DEVER-FAZER \\
\hline TENTAÇÃO & PODER (valores positivos) & QUERER-FAZER \\
\hline
\end{tabular}

Tabela I: Tipos de manipulação

Nas narrativas policiais, os criminosos são sujeitos de estado que se transformam em sujeitos do fazer, manipulados pela paixão malevolente que os afeta. Os estados resultantes dessas paixões fazem com que o sujeito adquira competência para poder e saber fazer mal ao outro. As paixões, segundo Greimas e Courtés (1983), distinguem-se entre paixões simples e paixões complexas. "As paixões simples resultam de um único arranjo modal, que modifica a relação entre o sujeito e o objeto-valor; enquanto as paixões complexas são efeitos de uma configuração de modalidades, que se desenvolve em vários percursos passionais". (BARROS, 2005, p. 47)

No programa da competência, o destinatário-sujeito recebe do destinador a qualificação necessária para realizar a ação: o criminoso adquire a oportunidade e, quando necessário, os instrumentos para cometer o crime; o detetive, por sua vez, inicia a investigação por meio de interrogatórios, da busca de pistas sobre o criminoso. Após adquirirem as competências, os sujeitos do fazer realizam suas perfórmances, ou seja, a ação criminosa e a ação investigativa, cujos resultados consistem no fato de o criminoso e o detetive apropriarem-se dos objetos-valor que desejam. O que diferencia as narrativas policiais é, justamente, o programa da perfórmance e, por isso, observamos, em nossa pesquisa, tipos de assassinato e de investigação diferentes entre si, ainda quando criados pelo mesmo autor, nas obras estudadas.

Por fim, vem a sanção, etapa na qual o destinador, geralmente representado pela polícia, interpreta as ações do destinatário-sujeito, julga-o e dá-lhe a retribuição devida, sob a forma de punições ou recompensas. A entrega dos criminosos à polícia, realizada pelo detetive, para que ela os sancione negativamente é uma das regras da sociedade burguesa na qual surgiu o gênero romance policial. Segundo essa sociedade, aquele que transgredir as regras sociais, de modo a estabelecer uma desordem, deve ser sancionado negativamente por aqueles que zelam pela ordem, a justiça e a polícia. Enquanto a sanção não ocorre na narrativa, o criminoso continua a realizar sua perfórmance, ou seja, enquanto não for sancionado pelo detetive, ele pode cometer novos crimes, uma vez que já adquiriu a competência necessária para esse fazer. O fazer do detetive, considerado o detetive metafórico $^{l}$, pode muitas vezes receber o auxílio dos chamados pseudodetetives, ou auxiliares do saber, também denominados detetives metonímicos, mas nenhuma outra personagem, que não o criminoso, sabe quem cometeu o crime. Isso normalmente ocorre para que o leitor não se sinta injustiçado por ser o único que ignora a identidade do criminoso. Mesmo nos romances policiais em que o criminoso tem algum amigo muito próximo ou parente, este só conhece sua identidade se for cúmplice do crime. Em outras palavras, podemos dizer que o criminoso é o único sujeito que detém o saber sobre sua identidade.

\footnotetext{
${ }^{1} \mathrm{O}$ detetive metafórico é o detetive propriamente dito; aquele que desvenda o crime por métodos lógicos, racionais. É assim considerado por ser o único sujeito da narrativa capaz de encontrar a identidade do criminoso.
} 
A respeito dos auxiliares do saber, Martins (2000, p. 85) explica que eles "levantam hipóteses ou fazem acusações ou julgamentos a partir de interpretações bastante subjetivas", ou seja, auxiliam o detetive sem ter plena consciência do que estão fazendo, pois lhe dão informações que aparentemente são dispensáveis, ou seja, não ordenadas de acordo com o mistério a ser resolvido. Segundo Martins (2000, p. 92), os pseudodetetives "querem resolver o crime, pois buscam informações a respeito dele e acompanham a investigação de perto", não conseguindo, porém, relacionar a vítima, o criminoso e o crime - o que reforça ainda mais a presença indispensável do detetive.

A sanção realizada pelo detetive sobre o fazer do criminoso foi classificada neste trabalho de acordo com a proposta de Martins (2000), que levou em conta três tipos de sanção: a sanção cognitiva, a sanção pragmática e a sanção cognitiva e pragmática ao mesmo tempo. Segundo o autor, na sanção cognitiva, que aparece nas narrativas de detetive, a busca da identidade do criminoso é a perfórmance a ser realizada pelo sujeito-detetive. O crime é realizado e um destinador-manipulador aciona o fazer do detetive, que não sabe quem cometeu o crime, mas que tem os instrumentos necessários para realizar essa descoberta. Já na sanção pragmática, que ocorre nas narrativas de criminoso, o sujeito-detetive conhece a identidade do criminoso quando é manipulado a realizar a investigação. Esse saber pode ser transmitido a ele pelo próprio destinador-manipulador ou por algum indício inegável acerca do crime. Mesmo que já conheça, porém, a identidade do criminoso, o detetive precisa persegui-lo para que consiga as provas necessárias para incriminá-lo e, conseqüentemente, prendê-lo. É importante lembrar que esse saber sobre a identidade do criminoso não implica o conhecimento, da parte do detetive, do nome do sujeito, mas sim de uma denominação que torne possível encontrá-lo. No terceiro tipo de sanção, a cognitiva e pragmática, as duas características aparecem simultaneamente, isto é, o detetive precisa descobrir a identidade do criminoso e perseguí-lo, tanto para provar que ele é o culpado, quanto para descobrir onde está escondido - o criminoso se esconde, pois sabe que foi descoberto por outro sujeito. Em geral, nos romances policiais, o criminoso, a vítima e o detetive permanecem, durante toda a narrativa, no mesmo espaço, que é também o local do crime e que pode ser um hotel, uma pensão, um trem, uma aldeia, entre outros.

Neste trabalho estabelecemos um corpus de vinte e seis romances policiais, selecionados a partir de um levantamento realizado por Cortina (2006) sobre o perfil do leitor brasileiro de 1966 a 2004. Nele, Cortina (2006) catalogou os livros mais vendidos no Brasil e, dentre eles, escolhemos os da década de 1970 como foco de nosso trabalho, selecionando todas as obras que se enquadravam no gênero romance policial. Esse enquadramento foi resultado da leitura da sinopse de todos os livros levantados e da classificação dada pelo próprio autor e por duas livrarias (Cultura e Saraiva).

Para cada um dos romances, descrevemos o percurso narrativo do sujeito criminoso e o percurso narrativo do sujeito detetive, em seus quatro programas narrativos. Tendo em vista que é na sanção, última etapa do esquema narrativo, que os dois percursos se encontram, seguimos a classificação de Martins (2000) para distingui-los. Não encontramos em nosso corpus, porém, nenhum romance policial que apresentasse o terceiro tipo de sanção, isto é, a cognitiva e pragmática ao mesmo tempo. Também vale lembrar que privilegiamos a sanção realizada pelo detetive sobre o criminoso, que é negativa, e não a sanção realizada pela sociedade sobre o detetive, que é positiva. Essa sanção realizada sobre o fazer do detetive não tem o mesmo destaque nos romances policiais que a outra porque esse sujeito, em geral, já é manipulado por aqueles que reconhecem sua competência, ou seja, quando o detetive é acionado, seu destinador-manipulador escolhe-o porque tem certeza de que ele será bem sucedido na realização de sua perfórmance e, por isso, oferece a ele alguma recompensa, que geralmente é financeira. 
A sanção realizada pelo detetive sobre o fazer do criminoso, portanto, pode ser classificada como cognitiva ou pragmática. Essa classificação está relacionada à motivação do sujeito criminoso e do sujeito detetive, para a realização de suas performances, e ao percurso narrativo desses dois sujeitos, em seus quatro programas narrativos.

A semiótica discursiva é a perspectiva teórico-metodológica que sustenta nossa pesquisa. O sentido de um texto, para a semiótica, é construído a partir de um percurso gerativo que se organiza em três níveis distintos: o nível das estruturas fundamentais, o nível das estruturas narrativas e o nível das estruturas discursivas. $\mathrm{O}$ estudo dos romances policiais parte do exame de um componente do nível narrativo, o esquema narrativo canônico, cujo objetivo principal consiste em mostrar como está organizado o fazer transformador do sujeito e os estados que ele altera. A partir do exame dos componentes do nível narrativo é que se estabelecerá sua relação com os elementos constituintes tanto do nível discursivo quanto do nível fundamental. Isso porque, de acordo com a proposta da semiótica, o sentido do texto constrói-se a partir da articulação entre os três níveis do chamado percurso gerativo.

Martins $(2005$, p. 171) trabalhou os romances policiais a partir da teoria semiótica e destacou o nível das estruturas narrativas como o mais importante para este tipo de texto:

A semiótica propõe um esquema narrativo canônico, um modelo de previsibilidade, que nos possibilita verificar, a partir da perfórmance do sujeito, isto é, da transformação que ele opera na narrativa, por quais manipulações ele passou, quais foram as competências que ele precisou adquirir para efetuar tal ação e, por fim, como ele vai ser julgado por ter realizado ou não o que lhe foi (auto)destinado.

O criminoso é o sujeito que desencadeia a transformação na narrativa quando sanciona negativamente a vítima. Em seguida, o detetive é acionado para encontrar ou prender o criminoso, exercendo, portanto, o papel de destinador-julgador. É esse encaixe dos percursos narrativos que sustenta o esquema narrativo dos textos e que se manifesta na superfície discursiva. Neste trabalho, analisamos o programa narrativo do destinador-julgador na medida em que ele sanciona a perfórmance do destinatário-sujeito, no caso, o criminoso.

Em sua dissertação de mestrado, Martins (2000) explica que a sanção realizada nos dois tipos de narrativas policiais aqui estudadas, as de detetive e as de criminoso, são diferentes. No primeiro caso, a sanção é um reconhecimento cognitivo, já que "descobrir o criminoso é mais importante do que saber o que vai acontecer a ele após essa descoberta" (MARTINS, 2000, p. 34). Já na sanção pragmática, "ressaltam-se a perseguição do detetive sobre o criminoso - conhecido e reconhecido pelo narrador - e, sobretudo, o modo como ele será castigado" (MARTINS, 2000, p. 34).

Fontanille (2007) discute a questão da previsibilidade do discurso, explicando que as perfórmances do detetive e do criminoso devem-se realizar efetivamente nos romances policiais para que esses sujeitos cumpram seus papéis na narrativa, ou seja, o criminoso precisa realizar o crime para se afirmar como tal e o detetive deve fazer a investigação para justificar seu surgimento na narrativa. O leitor, por sua vez, mantém expectativa em relação à realização do fazer desses sujeitos. Portanto, na sanção pragmática, além de já saber quem é o criminoso, o leitor sabe que o detetive conseguirá encontrá-lo. Por sua vez, a sanção cognitiva é mais misteriosa, já que, mesmo sabendo que o detetive encontrará um culpado, o leitor não sabe quem é o criminoso e acompanha a investigação para tentar encontrá-lo juntamente com o detetive ou, se houver indícios na narrativa, antes dele - o que raramente acontece. 
Foi a partir dessas questões específicas que estabelecemos, no corpus da pesquisa, a classificação dos diferentes livros ali elencados entre os dois tipos de sanção, a cognitiva e a pragmática. Estabelecida essa classificação, verificamos como esses elementos do esquema narrativo canônico eram organizados em cada uma das obras. A partir desse levantamento, também foi possível compreender como cada texto construía as relações próprias do nível narrativo para, num segundo momento, examinarmos como o sujeito manifestado no enunciado (o narrador), ou o sujeito da enunciação (o enunciador), discursiviza-as.

Após realizarmos a leitura de cada um dos vinte e seis romances policiais que integram nosso corpus, produzimos um resumo esquemático da trama narrativa de cada um deles e estabelecemos um levantamento de dados sobre a predominância dos dois diferentes tipos de sanção ${ }^{2}$ : cognitiva $(\mathrm{C})$ e pragmática $(\mathrm{P})$, conforme a tabela abaixo.

\begin{tabular}{|c|c|c|}
\hline TÍTULO & AUTOR & SANÇÃO \\
\hline A aventura do Pudim de Natal & Agatha Christie & C \\
\hline A casa torta & Agatha Christie & C \\
\hline A morte da Sra. McGinty & Agatha Christie & C \\
\hline A mulher diabólica & Agatha Christie & C \\
\hline A noite das bruxas & Agatha Christie & C \\
\hline A testemunha ocular do crime & Agatha Christie & C \\
\hline Assassinato no Expresso do Oriente & Agatha Christie & $\mathrm{C}$ \\
\hline Cai o pano & Agatha Christie & $\mathrm{P}$ \\
\hline Cipreste triste & Agatha Christie & $\mathrm{C}$ \\
\hline E no final a morte & Agatha Christie & $\mathrm{P}$ \\
\hline Mistério no Caribe & Agatha Christie & $\mathrm{C}$ \\
\hline Morte na Mesopotâmia & Agatha Christie & $\mathrm{C}$ \\
\hline Morte na rua Hickory & Agatha Christie & $\mathrm{C}$ \\
\hline O caso dos dez negrinhos & Agatha Christie & $\mathrm{P}$ \\
\hline O dia do Chacal & Frederick Forsyth & $\mathrm{P}$ \\
\hline O mistério de Sittaford & Agatha Christie & $\mathrm{C}$ \\
\hline O seqüestro do metrô & John Godey & $\mathrm{P}$ \\
\hline Os elefantes não esquecem & Agatha Christie & $\mathrm{C}$ \\
\hline Os primeiros casos de Poirot & Agatha Christie & $\mathrm{C}$ \\
\hline Os três ratos cegos & Agatha Christie & $\mathrm{P}$ \\
\hline Seguindo a correnteza & Agatha Christie & $\mathrm{C}$ \\
\hline Treze à mesa & Agatha Christie & $\mathrm{C}$ \\
\hline Um acidente & Agatha Christie & $\mathrm{P}$ \\
\hline
\end{tabular}

\footnotetext{
${ }^{2}$ O terceiro tipo de sanção, cognitiva e pragmática, foi eliminado deste trabalho, conforme já mencionado anteriormente, por não haver nenhum romance que tivesse essa característica.
} 


\begin{tabular}{|c|l|l|}
\hline Um brinde de cianureto & Agatha Christie & $\mathrm{C}$ \\
\hline Um corpo na biblioteca & Agatha Christie & $\mathrm{C}$ \\
\hline Um passe de mágica & Agatha Christie & $\mathrm{C}$ \\
\hline
\end{tabular}

Tabela II: Tipos de sanção nos romances policiais do corpus

Em nosso trabalho constatamos que a maioria dos romances analisados, $73 \%$, corresponde ao tipo da sanção cognitiva, denominado narrativa policial de detetive, enquanto os outros, $27 \%$, correspondem ao tipo da sanção pragmática, narrativa policial de criminoso. Conforme explicamos em nota de rodapé, nenhum dos romances é do tipo composto, ou seja, narrativa policial de detetive e de criminoso, em que se mesclam as sanções cognitiva e pragmática e na qual o criminoso "não só mantém um estado mentiroso (ou secreto) de sua identidade, como também se refugia, tentando evitar, assim, ambas as sanções, a cognitiva ou o reconhecimento de que ele é o criminoso, e a pragmática ou a punição propriamente dita". (MARTINS, 2005, p.177).

Nos dezenove romances policiais de sanção cognitiva, o detetive é um sujeito da trama narrativa que precisa observar as outras personagens para encontrar o assassino e cuja única vantagem é o direito legal de interrogar os suspeitos. Esse direito é atribuído a ele em função de sua competência para realizar a investigação. Todas as conversas do detetive e as pistas encontradas, porém, são apresentadas aos leitores, de modo que eles também podem desenvolver o mesmo trabalho que o detetive, mas não o fazem com a mesma eficácia, porque não têm a competência investigativa necessária. Além deles, a polícia também tem acesso a uma grande quantidade de informações, mas sempre se mostra incapaz de desvendar o crime, já que essa função específica é atribuída ao detetive. Em muitos casos, o destinadormanipulador do detetive é a própria polícia, que resolve contratá-lo após ter fracassado na investigação.

As formas de investigação dentro do grupo da sanção cognitiva são diferentes. O detetive pode se valer de testemunhas oculares, presenciais, auditivas, ou pode conseguir objetos que denunciem o criminoso, como cartas de revelação escritas para amigos ou parentes, objetos encontrados na cena do crime, ou pode ainda encontrá-lo simplesmente pelo uso de seu raciocínio lógico, como faz Hercule Poirot na maioria dos romances de Agatha Christie. Além do mais, em nosso trabalho encontramos dois tipos de detetive, que já haviam sido estabelecidos por Martins (2000) e que foram explicados anteriormente, o detetive metafórico e o detetive metonímico.

O detetive é indispensável ao romance policial já que, sem ele, o criminoso não é reconhecido como tal e não é sancionado por um destinador-julgador. Por isso é importante que o detetive seja competente e que realize sua perfórmance em um tempo curto. Em geral, quando o detetive é manipulado a fazer a investigação, o destinador-manipulador não estabelece um prazo para a realização da investigação, porém, em muitos casos, enquanto o criminoso não for sancionado, outros crimes poderão ocorrer. Esses crimes podem ser cometidos tanto porque já estavam previstos pelo criminoso quanto porque essas vítimas adquiriram informações que poderiam auxiliar o detetive, ou seja, elas poderiam ser auxiliares do saber ou pseudodetetives que vão fazer com que esse sujeito encontre o culpado pelo crime.

Hercule Poirot é o detetive mais importante de Agatha Christie e aparece em doze dos vinte e seis romances policiais estudados nesta pesquisa. Segundo o narrador de $A$ aventura do Pudim de Natal "(...) quando ele (Poirot) assumia uma missão, era quase sinônimo de ser bem sucedido" (CHRISTIE, 1978, p. 12). Miss Marple, por sua vez, é o 
segundo detetive mais importante de Agatha Christie e desempenha o papel do detetive metafórico em quase todos os romances em que aparece. Embora ela não seja um detetive profissional, como Hercule Poirot, tem a competência necessária à investigação por ser uma velhinha simpática, que parece não fazer mal a ninguém. Independente de quem seja o detetive, é importante que ele não erre ao apontar o criminoso, pois, se assim o fizer, um sujeito inocente será entregue ao destinador-julgador e o assassino fará novas vítimas. Em nosso corpus de pesquisa, os detetives que erraram na identificação do criminoso pertenciam à polícia e não tinham a mesma competência que um detetive profissional. Para reparar o erro entrava em cena um detetive competente, de modo que o criminoso era sempre encontrado e punido ao final do romance.

Desde quando o romance policial surgiu, no final do século XIX, os detetives não pertenciam à polícia, já que esta era composta, na época, por ex-criminosos em quem a população não confiava. Assim, os policiais querem sempre apontar como criminoso o sujeito que aparente mais culpa para que a investigação não consuma muito de seu tempo. A entrega dos criminosos ao destinador-julgador, realizada pelo detetive para que aquele os sancione negativamente, é uma das regras da sociedade burguesa na qual surgiu o gênero romance policial: aquele que transgredir as regras sociais, de modo a estabelecer uma desordem, deve ser sancionado negativamente por aqueles que zelam pela ordem, a justiça e a polícia.

O criminoso, por sua vez, sempre detém o saber sobre sua identidade e o guarda como segredo. Quando mais de um sujeito sabe quem é o criminoso, é porque alguém o ajudou a realizar a perfórmance, de modo que também pode ser culpado pelo crime, o que faz com que guarde o segredo da identidade de seu comparsa. Quando o criminoso está dando continuidade a sua perfórmance, ou seja, ele ainda não foi sancionado pelo detetive, e precisa fazer novas vítimas para evitar que isso aconteça, os crimes são cometidos da mesma maneira, já que são resultantes da mesma competência. Isso significa que, se a primeira vítima do criminoso foi empurrada de um penhasco, por exemplo, as demais também serão mortas dessa maneira, como ocorreu no romance policial E no final a morte, de Agatha Christie.

Faremos aqui um breve resumo de dois romances policiais, selecionados entre os vinte e seis estudados, para ilustrar o trabalho realizado. As obras são A morte da Sra. McGinty, que apresenta em sua constituição narrativa a sanção cognitiva, e Cai o pano, que apresenta a sanção pragmática, ambas de Agatha Christie.

No romance policial A morte da Sra. McGinty, o inspetor de polícia Spence tinha encerrado sua investigação sobre a morte da Sra. McGinty, atingida na cabeça por um objeto pesado e pontudo, apontando como culpado James Bentley, o caseiro dela, que seria enforcado três semanas após haver sido condenado pelo tribunal. Embora todos os indícios apontassem para James, Spence acreditava que ele não era o assassino e temia ter errado na investigação. Por isso, o inspetor entrou em contato com Hercule Poirot, um detetive profissional com quem ele tinha amizade, e pediu a ele que refizesse a investigação antes de James ser sancionado.

Apesar de ser bem velha, a Sra. McGinty trabalhava como faxineira na casa da Sra. Sweetiman e da Sra. Upward, que tinha um filho chamado Robin. Ele era adotado, mas quase ninguém sabia disso. McGinty costumava ler jornais e, certa vez, encontrou uma matéria sobre quatro assassinas com suas respectivas fotos. Ao vê-las, a velha reconheceu uma das fotos e escreveu ao jornal contando que conhecia uma das mulheres, Eva Kane. McGinty já tinha visto outra foto de Eva entre os pertences de Robin, atrás da qual estava escrito "minha mãe". Assim, a velha descobriu que a verdadeira mãe de Robin era uma assassina e tentou chantageá-lo querendo vender seu silêncio. Essa chantagem, porém, serviu de manipulação por provocação para que Robin se tornasse um criminoso. Nesse caso, o destinador-manipulador do fazer do criminoso tornou-se a própria vítima. 
Para adquirir a competência necessária à realização do crime, Robin apropriouse de um antigo "cortador de pedras de açúcar" muito grande, pesado e pontudo, comprado por sua mãe em um bazar da igreja. Ele sabia que McGinty morava sozinha e, por isso, foi até a casa dela realizar sua perfórmance, acertando-lhe um golpe na cabeça. Como a vítima tinha contado à mãe de Robin (e esta a ele) que guardava dinheiro debaixo do assoalho e pedido segredo por isso, o criminoso roubou o dinheiro a fim de incriminar o caseiro, James Bentley, que também deveria conhecer o esconderijo. Depois do crime, Robin livrou-se do cortador, levando-o para a arrecadação de prendas da igreja local. A perfórmance de Robin foi tão bem sucedida que outro sujeito, James Bentley, foi acusado pelo assassinato e Maureen Gregg, uma moradora daquela comunidade (que também era filha adotiva), comprou o cortador de açúcar no segundo bazar promovido pela igreja.

No dia seguinte, Robin descobriu que Hercule Poirot estava investigando a morte da Sra. McGinty e já sabia que o caso tinha relação com uma matéria sobre mulheres assassinas publicada no jornal há pouco tempo. Durante uma festa promovida pelo casal Carpenter, que morava na mesma comunidade, Poirot mostrou as fotos das assassinas para ver qual seria a reação dos convidados. Imediatamente, a Sra. Upward lembrou-se de que McGinty tinha lhe mostrado uma daquelas fotos e Robin percebeu o desespero que a mãe tentou esconder, mas que também foi notado pelo detetive. Assim, ele precisou dar continuidade a sua perfórmance criminosa eliminando Upward antes que ela descobrisse que ele havia matado a Sra. McGinty e contasse isso ao detetive. Uma vez mais, a vítima é o próprio destinador que manipula o criminoso Robin por provocação.

No dia seguinte, Robin encontrou uma boa oportunidade para realizar sua perfórmance. Convidou sua amiga Ariadne Oliver, com quem fazia teatro, para jantar na casa dele e depois ir ao cinema. Tendo garantido o testemunho de Ariadne para o álibi de que não estava em casa no dia da morte de Upward, Robin adquiriu a competência necessária para realizar o crime. Assim que saíram da casa dele, Robin fingiu ter esquecido a carteira e voltou para apanhá-la enquanto Ariadne esperava no carro. Assim, o criminoso pegou a velha de surpresa e a estrangulou com o lenço de seda que ela usava no pescoço ${ }^{3}$. Para completar sua perfórmance e não ser descoberto pelo esperto detetive, Robin levou a foto encontrada por McGinty em sua gaveta para a casa da amiga Maureen Gregg, a fim de incriminá-la, uma vez que ela tinha comprado o cortador de açúcar da Sra. Upward, usado por ele para matar McGinty.

Encerrado o percurso do criminoso, tem início o percurso do detetive. Hercule Poirot era um detetive profissional e foi manipulado por Spence para se tornar o sujeitodetetive. Ele deu início à sua perfórmance investigando todos os passos seguidos por Spence, a fim de descobrir onde o inspetor tinha errado. Poirot conversou com a Sra. Sweetiman, para quem McGinty também trabalhava, e ela contou-lhe que a velha faxineira tinha comprado um vidro de tinta e se mostrava perturbada nos dois dias que antecederam sua morte. O detetive resolveu conferir novamente os pertences da velha e encontrou os sapatos dela enrolados em uma folha de jornal. Nesse jornal, havia um grande recorte mostrando que alguma notícia tinha chamado a atenção de McGinty. O detetive conseguiu outro exemplar e, ao ler a matéria que estava faltando, deduziu que a vítima tinha sido assassinada após fazer alguma descoberta sobre um dos crimes publicados. Depois disso, Hercule Poirot conversou com a jornalista que tinha feito a matéria, a Srta. Horsefall, para saber se McGinty tinha entrado em contato com

\footnotetext{
${ }^{3}$ Nos romances policiais analisados nesta pesquisa, o criminoso raramente assassina alguém com quem tenha laços familiares (mãe, pai, irmão) ou amorosos (namorada, noiva, esposa). Pode acontecer, por exemplo, de a mãe assassinada pelo filho ser a mãe adotiva (A morte da Sra. McGinty) ou de o noivo não conseguir assassinar a noiva porque é impedido pelo detetive (Mistério no Caribe).
} 
ela. Segundo Horsefall, a velha lhe escrevera contando que tinha uma fotografia de uma das assassinas.

Durante a investigação de Poirot, um casal que morava no mesmo bairro que a Sra. McGinty, os Carpenter, promoveu uma festa para a qual foram convidados quase todos os moradores, mais Ariadne Oliver ${ }^{4}$, amiga de Robin e de Poirot, o detetive. Ariadne descobriu que Robin não era filho legítimo da Sra. Upward ao ouvi-lo conversar com Maureen Gregg, que também era adotada pelos pais. Na mesma festa, Poirot foi interrogado pelos convidados para que apontasse outro culpado, além de James Bentley, para a morte de McGinty. Aproveitando a situação, o detetive mostrou a eles a matéria do jornal e, espontaneamente, a Sra. Upward reconheceu uma das mulheres. Poirot percebeu que a velha ficara muito transtornada e começou a desconfiar que ela tinha feito a mesma descoberta que McGinty.

No dia seguinte, Upward foi assassinada, comprovando a teoria do detetive, e Ariadne contou a ele sobre a conversa entre Robin e Maureen. Mesmo sabendo que Ariadne estava com Robin no dia do crime, Poirot desconfiou dele e resolveu conversar com Maureen, de quem ele não suspeitava. Ao chegar à casa dela, encontrou um cortador de açúcar, que ela dizia ter comprado em um bazar da igreja, e imaginou que aquele instrumento poderia ter sido usado no assassinato de McGinty. Poirot revistou algumas gavetas e encontrou a foto de uma das mulheres da matéria, atrás da qual estava escrito "minha mãe". O detetive sabia que Maureen era adotada, mas ela negou que a foto fosse sua. Lembrou-se de que Robin também era adotado e que, por ser amigo de Maureen, tinha-a visitado naquele dia. Dessa forma, Poirot concluiu que ele havia deixado o cortador de açúcar na casa dela para incriminá-la. Robin havia assassinado a Sra. McGinty quando a encontrou em casa sozinha, porque ela sabia sobre sua verdadeira identidade, e, em seguida, matou a Sra. Upward, por ter feito a mesma descoberta, quando saiu do carro alegando ter esquecido sua carteira.

Assim, Hercule Poirot desvendou o mistério sobre a morte da Sra. McGinty e livrou James Bentley da forca. O detetive sancionou cognitivamente o criminoso Robin ao descobrir sua identidade e entregou-o ao detetive Spence, o destinador-manipulador, para que o punisse pelos dois crimes cometidos.

Nesse romance policial, a sanção é de ordem cognitiva por se tratar de uma típica narrativa policial de detetive, na qual o percurso do detetive em busca do criminoso é o foco central. Hercule Poirot foi invocado por Spence para encontrar o criminoso de um caso mal resolvido, cujo suposto culpado seria enforcado injustamente. $\mathrm{O}$ detetive percebeu, de início, que a primeira descoberta estava equivocada e conduziu a investigação em busca de provas mais concretas. Mesmo assim, não se trata de uma sanção pragmática, pois o criminoso apontado no início da narrativa não era o verdadeiro culpado, portanto, o destinador-julgador precisou iniciar a investigação como se nenhum outro investigador tivesse feito isso.

Partiremos agora para o outro romance policial, Cai o pano, em que a sanção é de ordem pragmática a fim de ilustrar as diferenças entre os dois tipos de sanção.

O famoso detetive londrino Hercule Poirot já estava muito velho, mas seu cérebro funcionava perfeitamente e, por isso, resolveu passar os últimos dias de sua vida perseguindo um criminoso procurado pela polícia havia vários anos. A manipulação de Hercule Poirot para perseguir um assassino, chamado Norton, deu-se a partir de cinco crimes

\footnotetext{
${ }^{4}$ Ariadne Oliver é uma personagem de Agatha Christie que apareceu em três romances analisados nesta pesquisa, quais sejam, A morte da Sra. McGinty, Os elefantes não esquecem e A noite das Bruxas. Em todos os casos, Ariadne é um auxiliar do saber, que fornece informações úteis ao detetive para que ele as organize e as relacione com o crime. É importante destacar que Ariadne faz parte do universo policial criado pela autora, de modo que em todas as obras ela aparece como amiga do detetive Hercule Poirot.
} 
cometidos por ele relatados nos jornais londrinos. As matérias referentes aos assassinatos mostravam a esperteza do criminoso e a incapacidade da polícia para encontrá-lo, o que motivou Poirot a assumir a investigação, ocorrendo assim uma manipulação por provocação.

A competência necessária a Poirot para realizar sua perfórmance foi adquirida quando ele descobriu o paradeiro do criminoso que pretendia perseguir 5 . Norton estava hospedado no hotel Styles e Poirot convidou o velho amigo Hastings para lhe fazer companhia enquanto se hospedava no mesmo hotel que o criminoso ${ }^{6}$. Ele pretendia deixar uma carta a Hastings explicando como e porque tinha sancionado Norton e, para isso, queria que o amigo acompanhasse a perseguição. Poirot, entretanto, não revelou a Hastings a identidade do criminoso e muito menos seus planos para persegui-lo. Poirot só contou a Hastings que um criminoso estava hospedado no hotel Styles e que ele pretendia impedi-lo de cometer outros crimes ${ }^{7}$. Além disso, Poirot fingiu-se de tetraplégico de modo que só se locomovia por meio de uma cadeira de rodas, usava bigodes e cabelos falsos e ainda fez uma cópia da chave do quarto de Norton. Assim, ele poderia sancionar o criminoso sem que ele desconfiasse de um velho inválido ${ }^{8}$.

Como Hastings é o narrador desse romance policial e desconhecia os segredos do detetive, o leitor também não sabe que Poirot já conhecia a identidade do criminoso e pretendia realizar uma sanção pragmática. $\mathrm{O}$ fato de Hastings ser o narrador impede o leitor de conhecer tanto o percurso narrativo do criminoso, que ocorrera em um momento anterior à narrativa principal, quanto alguns dos programas narrativos do detetive, que não são revelados ao amigo: Poirot não conta como havia descoberto que Norton se hospedaria no hotel Styles nem que estava disfarçado de paraplégico. Portanto é só ao final da narrativa, com a leitura de uma carta deixada por Poirot a Hastings, que o leitor consegue compreender que esse romance corresponde a uma narrativa de criminoso, na qual Hercule Poirot perseguia o criminoso Norton pelos crimes cometidos há alguns anos.

Para sancionar Norton por sua perfórmance criminosa, Poirot envenenou-o com morfina, fazendo com que ele morresse enquanto dormia. Pela manhã, Poirot entrou em seu quarto e colocou a pistola dele (Norton) na sua mão para simular um suicídio. Em seguida, Poirot deixou a chave do quarto no bolso de Norton e trancou a porta com a cópia de chave que tinha feito há alguns dias.

Após sancionar o criminoso pragmaticamente, Poirot resolveu se autosancionar pelo crime que tinha cometido. $\mathrm{O}$ fato de ter passado a vida toda sancionando criminosos contribuiu para que o detetive se sentisse no dever de também ser sancionado. Como ele guardava o segredo do crime que cometera e nenhum outro sujeito poderia sancioná-lo, restava-lhe a auto-sanção. Antes disso, porém, Poirot escreveu uma carta para Hastings contando tudo o que tinha feito e pediu a seu advogado que só a entregasse a Hastings quatro meses depois de sua morte.

\footnotetext{
${ }^{5}$ O leitor não fica sabendo como Poirot fez essa descoberta já que o narrador também não sabe; os motivos para isso são discutidos mais adiante.

${ }^{6}$ Hastings é uma das personagens do universo policial criado por Agatha Christie. Ele aparece em alguns dos romances estudados nesta pesquisa, o romance Cai o pano e os contos "O expresso de Plymouth" e "A caixa de chocolates", da coletânea Os primeiros casos de Poirot. Na maioria deles Hastings é amigo do detetive Hercule Poirot e narrador da história.
}

${ }^{7}$ Se Hastings detivesse todas essas informações seria injusto não compartilhá-las com o leitor, porém, se assim o fizesse, a narrativa não teria mistério nenhum.

${ }^{8}$ Esse disfarce de Poirot também é omitido de Hastings e, portanto, dos leitores. 
Hastings ainda tentou desvendar o mistério que atormentava seu amigo Hercule Poirot, mas não conseguia entender o que tinha acontecido a ele e ao suposto criminoso. Hastings não sabia se o crime previsto por Poirot ainda iria acontecer ou se tinha sido evitado pelo detetive, já que a morte de Norton indicava suicídio e a de Poirot, um ataque cardíaco.

Sendo assim, é só com a leitura da carta deixada por Poirot que o narrador Hastings e o leitor compreendem o percurso do criminoso e do detetive. Cai o pano é uma narrativa de detetive, na qual ocorre a sanção pragmática, pois o detetive sabe desde o início da narrativa quem é o criminoso, mesmo que não revele isso ao narrador, e seu fazer consiste em perseguir e punir o sujeito-criminoso. Apesar de não ter tido tempo de cometer o crime planejado para aquele momento, Norton era o criminoso porque já tinha se envolvido em outros casos e foi punido por Hercule Poirot, o detetive, por conta dos outros crimes cometidos. Se continuasse vivo, certamente faria mais vítimas em outras circunstâncias. É o próprio detetive, portanto, quem sanciona o criminoso e se vinga dele, assassinando-o e se matando em seguida. $\mathrm{O}$ destinador-julgador não apresentou suas provas à sociedade ou à polícia, mas fez justiça com as próprias mãos, eliminando o criminoso do grupo social ao qual pertencia.

Esses dois romances policiais foram escolhidos para apresentar os dois tipos de sanção, a cognitiva e a pragmática, por serem exemplos extremos dentro do corpus de pesquisa. Ou seja, o romance A morte da Sra. McGinty, de sanção cognitiva, apresenta o esquema narrativo canônico, proposto pela semiótica discursiva, e não foge a nenhuma das regras propostas pelo gênero romance policial. Já o romance Cai o pano, de sanção pragmática, embora também apresente o esquema narrativo canônico, desrespeita a regra fundamental de que o detetive não deve morrer durante o romance, já que ele é a personagem principal. Dessa forma, pretendemos mostrar que os romances policiais da década de 1970, embora apresentassem variações quanto à disposição dos elementos de sua narrativa, não fugiam muito dos padrões estabelecidos por esse gênero de romances.

A partir do levantamento sobre o tipo de sanção e da análise dos esquemas narrativos em cada um dos romances, procuramos explicar o porquê da predominância das narrativas de detetive, de sanção cognitiva, em nosso corpus de pesquisa. Nessas narrativas, o mistério se dá em relação à descoberta da identidade do criminoso, ao passo que na sanção pragmática não há mistério a ser desvendado: nela, o criminoso já é conhecido pelo detetive e, quase sempre, pelos leitores restando ao detetive encontrar as provas para incriminá-lo. Assim, na sanção pragmática o leitor quer saber como o detetive conseguirá incriminar o culpado e na sanção cognitiva ele quer descobrir quem é o assassino.

Portanto as narrativas de detetive se enquadram melhor no gênero romance policial por serem mais misteriosas, tanto é que, segundo nosso levantamento, essas narrativas são preferidas pelo leitor, aparecendo em $73 \%$ dos romances policiais mais vendidos na década de 1970. Outra prova de que a sanção cognitiva consiste em uma forma mais eficaz de manter o mistério é que sua característica mais marcante, a identidade oculta do criminoso, apareceu em muitos dos romances de sanção pragmática estudados nesta pesquisa. Isso ocorre quando o detetive já conhece a identidade do criminoso desde o início da narrativa, mas o narrador não sabe e não a revela ao leitor, de modo que este só fica sabendo o que aconteceu quando o detetive já encontrou as provas para incriminar o assassino.

Como o romance policial se caracteriza pelo mistério, é compreensível que a sanção cognitiva tenha prevalecido em nosso corpus de pesquisa, pois nela há o mistério acerca da identidade do criminoso, ao passo que na sanção pragmática ele já é conhecido e só resta ao detetive encontrar provas para incriminá-lo.

Todo romance policial tem um desenlace previsível, ou seja, o leitor já sabe, desde o início, que o criminoso vai conseguir realizar sua perfórmance sem ser descoberto e 
que, depois, o detetive também conseguirá realizar sua perfórmance e encontrar o criminoso. Isso porque, se não houver o crime, não haverá investigação e, assim, o romance policial perderá o seu sentido. Tendo em vista que os dois sujeitos, detetive e criminoso, conseguirão realizar suas perfórmances, a sanção pragmática torna-se menos misteriosa do que a sanção cognitiva. Isso porque, na sanção cognitiva, mesmo que o leitor já saiba que o detetive vai encontrar o criminoso, ele não sabe quem é esse sujeito e quer encontrar indícios que o ajudem a realizar a investigação, ou seja, o leitor tem uma motivação para a leitura e, com isso, presta mais atenção às ações realizadas pelo detetive, às falas e aos comportamentos das personagens, à descrição dos ambientes, enfim, ao desenrolar da narrativa. Por outro lado, na sanção pragmática, o leitor sabe desde o início quem é o criminoso e sabe que o detetive conseguirá encontrar provas para incriminá-lo, tanto porque, segundo o senso comum, "a verdade sempre aparece" quanto pela competência do detetive para realizar a investigação. Dessa forma, o único mistério pertinente à sanção pragmática é o como o detetive vai incriminar o culpado, o que, a nosso ver, nem pode ser considerado mistério, já que é relatado pelo próprio detetive ao longo da narrativa e o narrador não faz qualquer suspense quanto a isso.

\section{Referências bibliográficas}

BARROS, D. L. P. de. Teoria semiótica do texto. São Paulo: Ática, 2005.

CORTINA, A. Leitor contemporâneo: Os livros mais vendidos no Brasil de 1966 a 2004. Araraquara, 2006. Tese (Livre-docência) - Faculdade de Ciências e Letras, Universidade Estadual Paulista.

CHRISTIE, A. A aventura do pudim de Natal. Tradução Vânia A. Salek. Rio de Janeiro: Nova Fronteira, 1978, p. 9-46.

FONTANILLE, J. Semiótica do discurso. Tradução de Jean Cristus Portela. São Paulo: Contexto, 2007.

GREIMAS, A. J. Sobre o sentido: ensaios semióticos. Petrópolis: Vozes, 1975.

Dicionário de semiótica. Tradução de Alceu Dias Lima et alii. São Paulo: Cultrix, 1983.

MARTINS, M. M. Narrativa policial: uma abordagem semiótica. São Paulo, 2000. Dissertação (Mestrado) - Faculdade de Filosofia, Letras e Ciências Humanas, Universidade de São Paulo.

Constituintes do gênero policial: natureza, percursos e métodos de investigação. In: LOPES, I. C. \& HERNANDES, N. (Orgs.). Semiótica: objetos e práticas. São Paulo: Contexto, 2005, p. 169-189. 